\title{
Research on Scenario Simulation Teaching Method of Social Etiquette Course
}

\author{
Zhao Cuicui \\ Baicheng Normal University, Baicheng 137000, China \\ email: 18743607552@163.com
}

Keywords: Social Etiquette Course, Scenario Simulation Teaching Method, Research

\begin{abstract}
Since ancient times, our country is called a state of ceremonies. In modern society, with people or work, a person in the ceremonial performance will directly affect the actual work efficiency or exchange results. In this situation, some universities have carried out a social etiquette course to cultivate the students, but according to the current situation, most of the universities in this course are still not clear goals and plan for the concept of "social etiquette", this course must have strong practicality. Therefore, we can apply scenario simulation teaching method to fully in the process. In order to ensure the actual teaching effect. The implementation process of the actual study in detail.
\end{abstract}

\section{Introduction}

Mastering certain social etiquette is a critical means to ensure the students get better results in learning and work. According to the current situation, most of the employers in the recruitment process are not clear requirements for the quality, but in the actual work process often appears in college graduates because of lack of social etiquette master not with other colleagues or departments to effectively expand communication and collaboration, thereby affecting the work efficiency. For college students' interpersonal situation, in recent years in college because the students between the mouth and the occurrence of malignant events. More and more students to master the incomplete social etiquette is one of the main reasons of such phenomenon. Based on these two points it is very necessary to research on this problem. In this paper, we will firstly described the related concepts and background, and in the subsequent content of The teaching process is studied

\section{The Background and Related Concepts}

First of all, we have to carry out social etiquette courses in Colleges and universities in the background are analyzed[1]. In view of the needs of enterprises, has been briefly discussed above, in the actual process, the master degree of social etiquette is the foundation to ensure the normal development of the work process. Also, for students daily interpersonal communication, social etiquette the curriculum development can fundamentally avoid student conflict with others in the process, reduce the probability of occurrence of malignant campus events. For college students themselves, these students before entering university are not the collective life experience of middle school education also focuses more on theory knowledge, this also causes college students can easily produce contradictions in the process of getting along with others. If not timely to control or solve, the consequences will be very serious for. The above mentioned content, it is very necessary to carry out social etiquette course.

Secondly, we introduce the connotation of situational simulation teaching method[2]. Based on the discussion of social etiquette courses, social practice is the inevitable need of the number of two people or more than two people involved, and if teachers are still using the traditional theory of knowledge teaching method is difficult to obtain the good teaching effect. The application of situational teaching the method can solve the problem very well. As the name suggests, situational teaching method is dependent on certain actual situation in the process of teaching settings to assist students in the context of a better grasp of the teaching content. Obviously, use this way to assist the 
social etiquette course expansion can better guarantee the actual teaching effect.

\section{Instructional Design}

Context-Creating. Whether the situation is reasonable is the key influence of the implementation of this teaching method. In the process of creating real situations, teachers should do the following: first, teachers should ensure the selection of scenarios as close as possible to real life, the only way to ensure that students can better integrate into the situation in the teaching process. Secondly teachers should avoid creating situation, occupy a lot of time in class[3]. In essence, this application is still a kind of teaching method in order to assist the actual teaching process better. But if the teacher chooses the situation is too complicated, in the classroom to spend a lot of time to create such a situation, then the actual teaching effect but it The loss outweighs the gain.. Finally, teachers in the creation of situations should leave some suspense, this is the main method to ensure the students interested in teaching students through the problem. To learn, can greatly enhance the learning effect on the basis of teachers' simple explanation.

Extracurricular Preparation. Whether the extracurricular work fully prepared directly determine the actual classroom efficiency[4]. In this process, the teacher should invite students to participate fully in order to ensure there is no problem in the actual classroom. In actual work, we should complete the following two tasks: first, teachers should according to the teaching contents and students the status of implementation of situational teaching method should be selected in which part. Secondly, teachers should start before the actual implementation of the curriculum, the teaching method of the actual planning. For students, teachers can invite some students to exercise according to the existing schemes, when find the problem or the implementation process is not smooth, the teacher to timely modify the original program.

Classroom Presentation and Answering Questions. After the above two steps of preparation, demonstration stage teachers can guide students into practice. In this process, teachers should be students according to certain standards are divided into different groups, and then carry out the simulation demo. After the demo process is completed, can be formed by small demonstration group in class presentation and answering. In the process of teachers should pay attention to the following issues: first, teachers in this process should be fully the students in the main position, the enthusiasm of the students so as not to interrupt demonstration process so as not to affect the students. Secondly, teachers should conduct reviews in all groups after the demo, so as not to affect the subsequent process of demonstration team. Finally, in the process of answering, teachers should be guided and control, to ensure that students can fully on the question were discussed on the basis of the subject to avoid the deviation.

Analyze and Summarize. After answering demonstration should be analyzed separately summarized by teachers and students, this step is to ensure that students can achieve the key gaps. First of all, the process of presentation within the group to deal with different groups were analyzed and summarized, in this process, between different groups can be mutual learning. Second, teachers should on the whole. The students were summarized, analysis of existing problems, to help students find the cause of the problem, and in the next stage of learning to solve. At the same time, the performance of the students in this course, teachers should give students verbal or material reward, in order to ensure that students can be more active participate in that process[5].

\section{Teaching Examples}

For the implementation of situational simulation teaching method in social etiquette course, this article explains through the teaching of job hunting etiquette.

Firstly, we introduce the simulation figures in different teaching contexts. Usually, the job search process of college graduates mainly involves the following categories: job seekers, business reception staff, interview the examiner. The teacher can assign different students to play these roles in the process of the simulation, in order to ensure students can be more comprehensive look at the problem, teachers can guide the students during the presentation by changing roles to ensure the 
achievement of this goal[6].

Secondly, we introduced. the actual teaching process. When the job etiquette related content of teaching, the teacher should guide students to fully understand the job interview process the specific process and job seekers need to pay attention to the problem. In order to ensure the actual efficiency of the classroom, the teacher can also require students to complete the information before class through the network channels of the query, and by way of characters are summarized. Based on the full understanding of the job search process, we can set up several class recruitment requirements of different companies as the main recruitment unit. The examiner for simulation by students, this part of the students should be through the network, library and other the students in the form of preparation may ask questions during the interview, the interview process and try to ensure these questions in accord with the actual situation. Finally, teachers can organize Students with job seekers, business reception staff, job interview form to simulate. In the implementation of this step, the teacher should also set up a panel of judges in the class, by a panel of judges evaluate and score of the students' performance in different social etiquette. Finally, teachers can judge in group on the basis of the evaluation of the overall performance of students to summarize, analysis of existing problems, social etiquette to help students to have a better job in the actual process[7].

Finally, we simulate the situation of social etiquette in the course of implementation reflects the analysis of the advantages of teaching. For college students, the traditional teaching mode is likely to stimulate student interest in learning, in the actual teaching process, the participation of students in the classroom is not high enough, which leads to the social etiquette courses to achieve our goals. From the above job situation simulation, student participation in this process is very high, through the simulation of this type, the interest of the students will be able to get greatly improved. From the actual effect of teaching, college students in the job the actual process because no such training, probably because of the lack of social etiquette and give the interviewer a bad impression, thereby affecting the job search process of students. Through the above. Throughout the simulation, although the simulated situation and the actual situation there are some differences, but the live training to ensure that students must get more recognition in the application process. From the classroom efficiency, via the simulation demo, the classroom atmosphere will be greatly improved, the classroom efficiency will be improved.

\section{The Key in Application}

For the application of situational simulation teaching in social etiquette course, we should pay attention to the following problems, so as to ensure the actual application effect.

First, for the actual situation of the demonstration, because of the limited classroom time, it is difficult for us to ensure that all students are able to participate in this process, this part of the students in the classroom are likely to focus on the classroom situation. On the other hand, the students participate in the actual simulation the situation is likely to be for teachers because intentions affect the reality of this teaching method, and then makes the focus of the classroom deviate. For such problems, teachers should fully in the classroom to do global leadership in ensuring the participation of students at the same time to complete the task of teaching in the actual teaching process for. An example, teachers can encourage students to participate in the demonstration of no situation timely according to their own questions to ask questions, by asking the question - answer to ensure the students can better will note Yili on teaching content. When the class key deviation due to improvise students, teachers should timely intervention, help students better to complete the demonstration process.

Second, to carry out social etiquette courses, teachers should focus on students to master the etiquette, but not for teaching. Based on the process of situational teaching method, students in the actual situation of the demonstration, teachers should focus on students in manners, language, ability in terms of performance, not only rely on textbooks to evaluate student performance. In this process, teachers in addition to completing the theoretical teaching, should still be further guidance on students' performance in social etiquette, job etiquette mentioned above still in case teaching in this part the content, teachers should guide students how to exchange the better with the interviewer, 
avoid the students in the process of actual job because of the lack of etiquette and influence the result of your application.

Third, as I mentioned above, simulation activity is usually carried by the group as the unit, and in this process, different students may have different views on the same condition. At this time, students will be inside the team because these differences and conflict. If teachers can not timely guidance is may affect the process of demonstration practice, which led to the teaching effect decreased. When such a problem, teachers should first understand the dispute reasons of students, and fully listen to the opinions of different students, according to the actual situation to give advice. If students are there reasons or reason, so teachers should affirm these students the method and interpretation from different angles to guide the students during the presentation. If students view the wrong, then teachers can further to provide students more For more information, assist students to carry out further discussion, and then reach a consensus within the group.

Fourth, in the process of discussion, we have stressed the main role of the students, for the application of situational teaching method, teachers should pay attention to is to reflect the students' subject position in the teaching process. In the actual teaching process, teachers should actively the students fully mobilized. To encourage students to actively participate in the classroom context. Secondly, teachers should be dominant in the classroom to the students, to encourage students to play in the process of their ability, positive innovation, so as to achieve better teaching effect.

\section{Conclusion}

In summary, application of situational teaching method in social etiquette course is very meaningful, we should vigorously promote in the actual teaching process.

\section{References}

[1] Hua Hongzhen. Research on teacher's responsibility and role orientation in scene simulation teaching[J].Journal of Guangxi College of Education,2014,(5).

[2] Shi Xuefeng. Research on modern teaching mode of social etiquette course[J].Western China Quality Education,2016,2(17).

[3] Wang Yue. The impact of social etiquette on College Students' Employment[J].Northern Literature, 2017,(8).

[4] Shen Chune.The application of situational teaching method in the course of social etiquette [J]. Literature Education,2016,(6).

[5] Zhao Li.Application and development of teaching cases of social etiquette course[J].Journal of Jilin TV \& Radio University,2016,(1).

[6] Bao Yuehua. Exploration of innovative approaches to social etiquette course teaching[J]. Education, 2014, (12).

[7] Huang Meiqiong,Zhuang Lihong.The reform and practice of social etiquette course teaching mode-Taking Jimei University as an example [J]. Journal of Jimei University,2016,17(4). 